\title{
Crescimento inicial da parte aérea e do sistema radicular de três cultivares de alfafa ${ }^{1}$
}

\author{
Adriano C. Fernandes ${ }^{2}$, Teresinha de J. D. Rodrigues ${ }^{3}$, Euclides B. Malheiros ${ }^{4}$ \& Luis R. de A. Rodrigues ${ }^{5}$ \\ 1 Parte da Dissertação de Mestrado apresentada pelo primeiro autor à FCAV/UNESP \\ ${ }^{2}$ Av. Prudêncio Ortiz 257, Bairro Xis, CEP 14870-690, Jaboticabal, SP. Fone: (16) 3202-4573. E-mail: \\ adrifer@fcav.unesp.br (Foto) \\ ${ }^{3}$ FCAV/UNESP, Departamento de Biologia Aplicada à Agropecuária, Via de acesso Prof. Paulo D. Castellane, \\ CEP 14884-900, Jaboticabal, SP. E-mail: tedelro@fcav.unesp.br \\ ${ }^{4}$ FCAV/UNESP, Departamento de Ciências Exatas, E-mail: euclides@fcav.unesp.br \\ ${ }^{5}$ FCAV/UNESP, Departamento de Zootecnia, E-mail: Irodrigs@fcav.unesp.br
}

Protocolo 205 - 18/12/2003 - Aprovado em 5/4/2004

\begin{abstract}
Resumo: Esta pesquisa foi realizada com o intuito de se avaliar o sistema radicular em diferentes profundidades e o crescimento da parte aérea de três cultivares de alfafa (Medicago sativa L.), cultivadas em tubos preenchidos com areia, em casa-de-vegetação. Na semeadura, utilizaram-se sementes inoculadas com rizóbio específico. Os tubos foram irrigados com água e/ou solução de Hoagland $50 \%$ (uma vez por semana). Utilizou-se o delineamento inteiramente casualizado com três cultivares e cinco repetições para as variáveis referentes à parte aérea, e em parcelas subdivididas para as variáveis relativas ao sistema radicular. As plantas foram avaliadas aos 70 e 124 dias após a semeadura (DAS). Constataram-se diferenças significativas na altura das plantas das cultivares Crioula e Xai-32, aos 70 DAS, e entre a Crioula e 5454, aos 124 DAS. Houve diferença significativa entre as cultivares Xai-32 e 5454 aos 70 DAS, para as variáveis número de folhas e de ramos. Constatou-se diferença significativa entre as médias de densidade de comprimento radicular da primeira camada e as camadas inferiores, nas duas avaliações. As três cultivares de alfafa não diferiram entre si quanto ao número total de nódulos e à razão parte aérea / raiz.
\end{abstract}

Palavras-chave: Medicago sativa L, leguminosa forrageira, razão parte aérea/raiz

\section{Initial growth of shoot and root of three alfalfa cultivars}

\begin{abstract}
The main objective of this research was to evaluate the root system in different depths and the canopy growth of three alfalfa (Medicago sativa L.) cultivars grown in tubes filled with sand, under greenhouse conditions. The sowing was performed using inoculated seeds. All tubes were irrigated with water and or Hoagland solution - 50\%, once a week. A completely randomized design was used with three cultivars and five replications for canopy evaluation, and a split-plot (depths) for the root system evaluation. The plants were evaluated 70 and 124 days after sowing (DAS). Significant differences were observed for plant height of Crioula and Xai-32 cultivars at 70 DAS and between cultivar Crioula and 5454 at 124 DAS. Leaf and branch number of cultivars Xai-32 and 5454 were different at 70 DAS. Root length density in the first soil layer differed from those of the lower depths in both evaluations. There was no significant difference among the three cultivars in total number of nodules and in the shoot/root ratio.
\end{abstract}

Key words: Medicago sativa L, forage legume, shoot to root ratio

\section{INTRODUÇÃO}

A maioria das pesquisas com plantas tem-se concentrado no crescimento, desenvolvimento e funcionamento da parte aérea. A inclusão de raízes em estudos tem sido restrita a medidas de massa de raízes ao final do experimento, para determinar a relação raiz/parte aérea. Raramente são mensurados o comprimento e a área superficial das raízes, características que permitem avaliar a área potencial para absorção de água e minerais do solo e sua relação com o dossel. Fick et al. (1988) revisaram os principais estudos sobre ecofisiologia da cultura de alfafa (Medicago sativa L.) e assinalaram que os 
componentes da produção são função da taxa de crescimento vegetativo e da morfologia da planta. Os componentes da produção de uma cultura forrageira, são: 1) número de plantas por unidade de área; 2) número de ramos (ou perfilhos) por planta, e 3) massa de cada ramo individual. A área foliar e a massa das folhas em cada ramo são, comumente, medidas porque elas interligam os componentes da produção aos estudos de fisiologia e o valor nutritivo das folhas. Algumas vezes, a área ocupada pela planta é considerada medida indireta do número de ramos por planta.

O número de ramos por planta de alfafa aumenta com a idade, mas em qualquer ciclo de crescimento o máximo se estabelece, usualmente, 14 dias após o início da rebrota e depois declina à medida que o dossel se desenvolve (Nelson \& Smith, 1968; Singh \& Winch, 1974). No ano da semeadura, McLaughlin \& Christie (1980) observaram que o número médio de ramos por planta de alfafa aumentou de 2,4 a 3,9 para 6,2 e 6,5 , em quatro colheitas sucessivas.

Nabinger et al. (1999) incluíram a alfafa entre as leguminosas forrageiras perenes de inverno que são utilizadas em pastagens do Paraná, Santa Catarina e Rio Grande do Sul, juntamente com trevo branco, trevo vermelho e cornichão.

Silva et al. (1996) acompanharam as modificações na relação folha/caule de plantas de alfafa, em quatro períodos após cortes de uniformização. Em geral, os valores foram mais elevados no primeiro período, no qual se registraram valores acima de três nos primeiros dias de crescimento. A relação foi diminuindo em todos os períodos sempre que as plantas cresceram (até 80 dias). Após 50 dias de crescimento, a relação folha/caule foi menor ou igual a um, nos quatro períodos avaliados.

A profundidade radicular da alfafa aumenta de acordo com a idade do estande. O sistema radicular é fortemente dominado pela raiz principal, que pode ramificar em várias raízes secundárias. Tem-se observado grandes diferenças entre cultivares quanto ao número de raízes secundárias e a freqüência de raízes principais, que ramificam. Raízes fibrosas proliferam nos primeiros $20 \mathrm{~cm}$ do perfil do solo e têm, como característica, grande número de nódulos. A quantidade de raízes fibrosas e a eficiência da fixação de nitrogênio pelos nódulos das raízes, estão sob controle genético (Heichel, 1983).

Quando cortados, os nódulos apresentam, em geral, coloração rósea ou vermelha, fenômeno que pode ser uma indicação de que está havendo fixação de nitrogênio e, também, coloração branca e preta (Mitidieri, 1983). Ao longo das raízes secundárias ocorre a formação de nódulos indeterminados, de forma cilíndrica, e meristema terminal. Esta característica favorece maior resistência à seca e à salinidade, em relação com os nódulos determinados, tendo potencial para regenerar a atividade das estruturas afetadas por fatores de estresse (Bordeleau \& Prevóst, 1994).

Quanto ao sistema radicular Goins \& Russele (1996) enfatizaram que a sua arquitetura parece influenciar a absorção de nutrientes e a eficiência no uso da água, assim como afetar a partição de assimilados entre a parte aérea e as raízes. Esses autores observaram que, representando mais da metade, as raízes finas de alfafa que se localizam nos primeiros $20 \mathrm{~cm}$ do solo, são produzidas nas primeiras sete semanas de crescimento e, ainda, que a seleção de características de raízes de alfafa, como número de raízes laterais e massa de raízes fibrosas, pode dar bom resultado, já que os quatro genótipos estudados apresentaram grande variabilidade genética quanto à arquitetura e dimensão do sistema radicular.

Edmisten \& Wolf(1988), trabalhando com alfafa, concluíram que a rebrota de outono e a manutenção da planta, não foram dependentes do acúmulo de carboidratos não-estruturais na raiz e, ainda, que a fotossíntese compensa as perdas pela respiração e pela rebrota, durante o outono. Youngner (1972), afirma que as reservas de carboidratos se acumulam durante períodos em que a temperatura é favorável à fotossíntese, mas sub-ótima para o crescimento das folhas.

Monteiro et al. (1998) analisaram a produção e distribuição de matéria seca e a composição bromatológica de dezessete cultivares de alfafa e constataram que, no verão, o teor de proteína bruta na matéria seca variou de 17,74 a 20,82\% e, no inverno, de 19,82 a $23,63 \%$ entre as cultivares estudadas. A cultivar Crioula apresentou $19,22 \%$ no verão e $20,47 \%$ no inverno.

Assim, o objetivo principal desta pesquisa foi avaliar, comparativamente, a distribuição do sistema radicular em diferentes profundidades do solo e o crescimento da parte aérea de três cultivares de alfafa cultivados em tubos em condições de casa de vegetação.

\section{MATERIAL E MÉTODOS}

Para o estudo do desenvolvimento da parte aérea e sistema radicular da alfafa (Medicago sativa L.), foram utilizadas sementes de três cultivares, denominadas Crioula, Xai32 e 5454. O experimento foi conduzido em tubos de PVC com 1,00 m de comprimento e $0,20 \mathrm{~m}$ de diâmetro, seccionados longitudinalmente para propiciar um fracionamento mais prático do sistema radicular das plantas. As duas metades dos tubos foram montadas com três abraçadeiras e vedação dupla, com fita adesiva para embalagem (5 cm de largura). A abraçadeira da base prendia um pedaço de plástico perfurado para funcionar como dreno para o sistema. O substrato utilizado foi areia grossa peneirada, lavado várias vezes em água corrente, até que estivesse totalmente limpo e secado ao sol e estufa, a $70{ }^{\circ} \mathrm{C}$, antes de ser colocado nos tubos. O experimento foi desenvolvido em casa-de-vegetação do Departamento de Biologia Aplicada à Agropecuária da Faculdade de Ciências Agrárias e Veterinárias - UNESP, Campus de Jaboticabal, SP. Antes da semeadura realizou-se uma irrigação para possibilitar o assentamento melhor do substrato, em abril de 1998, na qual se utilizaram sementes inoculadas com bactérias do gênero Rhizobium meliloti, específico para a alfafa. Misturou-se o inoculante adquirido no comércio com as sementes levemente umedecidas, sendo 10 repetições por cultivar, semeadas diretamente nos tubos de PVC. Após a emergência das plântulas fez-se um desbaste, deixando-se uma planta por tubo. Aplicou-se, semanalmente, solução nutritiva de Hoagland 50\% e, diariamente, observou-se a condição de umidade do substrato e, sempre que necessário, o mesmo foi molhado com água. Foram realizadas duas avaliações das plantas, aos 70 e aos 124 dias após a semeadura (DAS). 
O delineamento experimental utilizado foi inteiramente casualizado, com números iguais de repetições, sendo 3 cultivares (Crioula, Xai-32 e 5454) e 5 repetições, para determinação de altura, número de folhas, número de ramos, área foliar, massa seca de lâminas, massa seca de caules e pecíolos, massa seca de inflorescência, massa seca de frutos e massa seca total da parte aérea das plantas de alfafa. Utilizouse também o delineamento experimental inteiramente casualizado, num esquema em parcelas subdivididas, sendo 3 parcelas (Crioula, Xai-32 e 5454), 5 subparcelas (profundidades $0,20,0,40,0,60,0,80$ e 1,0 m) e 5 repetições, para determinação do comprimento de raízes, densidade de comprimento de raízes, massa seca de raízes, número de nódulos, massa fresca de nódulos e massa seca de nódulos. As análises de variância e as comparações entre médias feitas pelo teste de Tukey $(\mathrm{P}<0,05)$, foram realizadas através do programa ESTAT - Sistema para Análises Estatísticas (V. 2.0). Nas avaliações aos 70 e 124 DAS, foram feitos os cortes da parte aérea para determinação da altura da planta, medida diretamente. Foi contado o número total de folhas das plantas. Na avaliação aos 70 DAS, mediu-se a área foliar com o total de folhas das plantas e, aos 124 dias, com uma sub-amostra de 20 folhas de cada planta. A massa seca de lâminas, de caules, de pecíolos, de inflorescências e de frutos, foi determinada utilizando-se estufa com circulação forçada de ar a $70^{\circ} \mathrm{C}$, pelo período de 48 horas.

O sistema radicular foi retirado em frações de $20 \mathrm{~cm}$ de profundidade, separado da areia e armazenado em vidros identificados contendo álcool $20 \%$ para conservação em geladeira, até o momento das análises. Para análise do sistema radicular retirou-se, de cada amostra, uma sub-amostra de $1,0 \mathrm{~g}$ cujo comprimento foi determinado pelo método das intersecções (Tennant, 1975; Rodrigues, 1984).

Após a retirada da sub-amostra e determinação do comprimento nas diferentes profundidades, as raízes foram colocadas para secar em estufa de circulação forçada de ar a $70{ }^{\circ} \mathrm{C}$, para determinação da massa seca de raízes nas diferentes profundidades. O comprimento total das raízes foi determinado relacionando-se a massa seca e o comprimento das raízes da sub-amostra com a massa seca total da amostra. Após a obtenção dos dados de comprimento radicular, realizou-se o cálculo da densidade de raízes nas diferentes profundidades do tubo. Para tal, dividiu-se o comprimento da raiz pelo volume do segmento, que é igual a $\mathrm{V}=\pi \mathrm{R}^{2} \times \mathrm{h}=3,14 \times\left(10^{2}\right) \times 20=$ $6280 \mathrm{~cm}^{3}$. Os resultados foram expressos em $\mathrm{cm}$ de raiz por $\mathrm{cm}^{3}$ de substrato. A razão parte aérea/raiz, foi calculada dividindose a massa seca total da parte aérea pela massa seca total do sistema radicular. Determinou-se também o número de nódulos nas diferentes profundidades, número de nódulos total, massa fresca de nódulos nas diferentes profundidades, massa seca de nódulos nas diferentes profundidades, massa seca de nódulos total e massa seca total da planta (massa seca de raízes total + massa seca de nódulos total + massa seca total da parte aérea).

\section{RESULTADOS E DISCUSSÃO}

As médias para altura das plantas obtidas para as três cultivares de alfafa (Tabela 1) apresentaram diferença significativa entre a cultivar Crioula e a Xai-32, aos 70 DAS.
Tabela 1. Valores médios ${ }^{\S}$ de altura (A), número de folhas(NF), número de ramos (NR) e área foliar (AF) de três cultivares de alfafa, em duas épocas de avaliação

\begin{tabular}{llllll}
\hline \multirow{2}{*}{ Época } & \multirow{2}{*}{ Estatística } & \multicolumn{4}{c}{ Variáveis Estudadas (Parte aérea) } \\
\cline { 3 - 6 } & & $\mathrm{A}(\mathrm{cm})$ & $\mathrm{NF}^{+}$ & $\mathrm{NR}^{+}$ & $\mathrm{AF}\left(\mathrm{cm}^{2}\right)$ \\
\hline \multirow{4}{*}{70 dias } & Crioula & $38,12 \mathrm{~B}$ & $5,16 \mathrm{AB}$ & $2,82 \mathrm{AB}$ & $53,32 \mathrm{~A}$ \\
& Xai-32 & $47,50 \mathrm{~A}$ & $5,71 \mathrm{~A}$ & $3,16 \mathrm{~A}$ & $67,92 \mathrm{~A}$ \\
& 5454 & $43,44 \mathrm{AB}$ & $4,42 \mathrm{~B}$ & $1,89 \mathrm{~B}$ & $52,24 \mathrm{~A}$ \\
& $\mathrm{~F}$ (tratamento) & $4,42^{*}$ & $5,68^{*}$ & $3,99^{*}$ & $1,86^{\mathrm{ns}}$ \\
& $\mathrm{CV}(\%)$ & 11,63 & 11,92 & 27,91 & 24,85 \\
\hline \multirow{4}{*}{124 dias } & Crioula & $73,00 \mathrm{~B}$ & $15,77 \mathrm{~A}$ & $4,09 \mathrm{~B}$ & $480,68 \mathrm{~A}$ \\
& Xai-32 & $91,10 \mathrm{AB}$ & $20,05 \mathrm{~A}$ & $4,69 \mathrm{~A}$ & $478,37 \mathrm{~A}$ \\
& 5454 & $108,80 \mathrm{~A}$ & $18,23 \mathrm{~A}$ & $4,85 \mathrm{~A}$ & $625,90 \mathrm{~A}$ \\
& $\mathrm{~F}$ (tratamento) & $12,31^{* *}$ & $1,05^{\mathrm{ns}}$ & $14,63^{* *}$ & $0,96^{\mathrm{ns}}$ \\
& CV (\%) & 12,54 & 26,04 & 5,13 & 36,57 \\
\hline
\end{tabular}

${ }^{8}$ Médias seguidas de letras iguais na mesma coluna, não diferem pelo teste de Tukey, a $5 \%$ de probabilidade

Dados transformados em $\sqrt{X}$

* Significativo a $5 \%$ de probabilidade; ** Significativo a $1 \%$ de probabilidade; ${ }^{\text {ns }}$ Não significativo a $5 \%$ de probabilidade

Observa-se maior altura das plantas da cultivar Xai-32, seguida das cultivares 5454 e Crioula, aos 70 DAS. Quando se comparam as médias para altura das plantas obtidas para as três cultivares aos 124 DAS, nota-se diferença significativa entre a Crioula e a 5454, apresentando maior valor para a cultivar 5454, seguida das cultivares Xai-32 e Crioula. Nesta data, a cultivar 5454 ultrapassou a altura média de $1,0 \mathrm{~m}$ descrita para a espécie (Mitidieri, 1983; Nuernberg et al. 1990).

As médias para número de folhas obtidas para as cultivares de alfafa Xai-32 e 5454 (Tabela 1) apresentaram diferença significativa entre si aos 70 DAS. Constata-se maior número de folhas das plantas da cultivar Xai-32, seguida das cultivares Crioula e 5454. Quando se comparam as médias para número de folhas obtidas para as três cultivares aos 124 DAS, tem-se au-sência de diferença significativa entre as três cultivares (Tabela 2).

As médias obtidas (Tabela 3), indicaram, aos 70 como aos 124 DAS, diferença significativa entre o comprimento e a densidade de comprimento de raízes encontradas na primeira

Tabela 2. Valores médios ${ }^{\S}$ de massa seca de lâminas (L), de caules mais pecíolos $(\mathrm{C}+\mathrm{P})$, de inflorescências $(\mathrm{I})$, de frutos (F) e total da parte aérea (PA) de três cultivares de alfafa, em duas épocas de avaliação

\begin{tabular}{llllll}
\hline \multirow{2}{*}{ Estatística } & \multicolumn{5}{c}{ Variáveis Estudadas (Parte aérea) / Massa seca (g) } \\
\cline { 2 - 6 } & \multicolumn{1}{c}{$\mathrm{L}$} & $\mathrm{C}+\mathrm{P}$ & $\mathrm{I}^{+}$ & $\mathrm{F}^{+}$ & $\mathrm{PA}$ \\
\hline Época 70 dias & & & & & \\
Crioula & $0,134 \mathrm{~A}$ & $0,162 \mathrm{~B}$ & - & - & $0,295 \mathrm{~B}$ \\
Xai-32 & $0,196 \mathrm{~A}$ & $0,266 \mathrm{~A}$ & - & - & $0,463 \mathrm{~A}$ \\
5454 & $0,128 \mathrm{~A}$ & $0,216 \mathrm{AB}$ & - & - & $0,347 \mathrm{AB}$ \\
F (tratamentos) & $3,99 *$ & $5,77^{*}$ & - & - & $6,00^{*}$ \\
CV $(\%)$ & 27,61 & 22,55 & - & - & 21,26 \\
\hline
\end{tabular}

Época 124 dias

\begin{tabular}{llllll} 
Crioula & $1,902 \mathrm{~A}$ & $2,998 \mathrm{~A}$ & $0,82 \mathrm{~A}$ & $1,15 \mathrm{~A}$ & $5,99 \mathrm{~A}$ \\
Xai-32 & $2,822 \mathrm{~A}$ & $4,680 \mathrm{~A}$ & $0,91 \mathrm{~A}$ & $1,11 \mathrm{~A}$ & $8,72 \mathrm{~A}$ \\
5454 & $2,348 \mathrm{~A}$ & $5,108 \mathrm{~A}$ & $0,88 \mathrm{~A}$ & $1,12 \mathrm{~A}$ & $8,66 \mathrm{~A}$ \\
$\mathrm{~F}($ tratamentos $)$ & $0,96^{\mathrm{ns}}$ & $1,12^{\mathrm{ns}}$ & $0,39^{\mathrm{ns}}$ & $0,01^{\mathrm{ns}}$ & $0,65^{\mathrm{ns}}$ \\
$\mathrm{CV}(\%)$ & 44,47 & 55,19 & 17,29 & 35,71 & 55,66 \\
\hline
\end{tabular}


Tabela 3. Valores médios ${ }^{\S}$ de comprimento (C), densidade (DR) e massa seca total (MST) de raízes de três cultivares de alfafa, em duas épocas de avaliação

\begin{tabular}{|c|c|c|c|c|}
\hline \multirow[b]{2}{*}{ Época } & \multirow[b]{2}{*}{ Estatísticas } & \multicolumn{3}{|c|}{ Variáveis Estudadas (Sistema radicular) } \\
\hline & & $\begin{array}{c}\mathrm{C}^{+} \\
(\mathrm{cm})\end{array}$ & $\begin{array}{c}\mathrm{DR}^{+} \\
\left(\mathrm{cm} \mathrm{cm}^{-3}\right)\end{array}$ & $\begin{array}{c}\mathrm{MST}^{+} \\
(\mathrm{g})\end{array}$ \\
\hline & F para cultivar $(\mathrm{C})$ & $0,53^{\mathrm{ns}}$ & $0,75^{\text {ns }}$ & $0,16^{\mathrm{ns}}$ \\
\hline & Profundidade (P) & $164,98^{* *}$ & $128,91^{* *}$ & $162,21^{* *}$ \\
\hline & Interação (CxP) & $1,42^{\mathrm{ns}}$ & $1,29^{\mathrm{ns}}$ & $0,71^{\mathrm{ns}}$ \\
\hline & CV (\%) parcela & 13,44 & 4,22 & 1,42 \\
\hline & CV (\%) subparcela & 13,74 & 4,33 & 1,38 \\
\hline \multirow{13}{*}{70 dias } & C1 (Crioula) & $0,893 \mathrm{~A}$ & $0,751 \mathrm{~A}$ & $0,723 \mathrm{~A}$ \\
\hline & C2 (Xai-32) & $0,917 \mathrm{~A}$ & $0,757 \mathrm{~A}$ & $0,722 \mathrm{~A}$ \\
\hline & C3 (5454) & $0,882 \mathrm{~A}$ & $0,745 \mathrm{~A}$ & $0,721 \mathrm{~A}$ \\
\hline & P1 $(0-20 \mathrm{~cm})$ & $1,628 \mathrm{~A}$ & $0,921 \mathrm{~A}$ & $0,780 \mathrm{~A}$ \\
\hline & P2 $(20-40 \mathrm{~cm})$ & $0,732 \mathrm{~B}$ & $0,711 \mathrm{~B}$ & $0,709 \mathrm{~B}$ \\
\hline & P3 $(40-60 \mathrm{~cm})$ & $0,712 \mathrm{~B}$ & $0,707 \mathrm{~B}$ & $0,707 \mathrm{~B}$ \\
\hline & P4 $(60-80 \mathrm{~cm})$ & $0,707 \mathrm{~B}$ & $0,707 \mathrm{~B}$ & $0,707 \mathrm{~B}$ \\
\hline & P5 $(80-100 \mathrm{~cm})$ & $0,707 \mathrm{~B}$ & $0,707 \mathrm{~B}$ & $0,707 \mathrm{~B}$ \\
\hline & F para cultivar $(\mathrm{C})$ & $0,58^{\mathrm{ns}}$ & $0,54^{\mathrm{ns}}$ & $0,15^{\mathrm{ns}}$ \\
\hline & Profundidade $(\mathrm{P})$ & $39,71^{* *}$ & $40,05^{* *}$ & $104,85^{* *}$ \\
\hline & Interação (CxP) & $1,00^{\mathrm{ns}}$ & $0,68^{\mathrm{ns}}$ & $0,99^{\mathrm{ns}}$ \\
\hline & CV (\%) parcela & 42,39 & 22,91 & 32,98 \\
\hline & CV (\%) subparcela & 24,03 & 13,87 & 13,50 \\
\hline \multirow{8}{*}{124 dias } & C1 (Crioula) & $1,706 \mathrm{~A}$ & $0,963 \mathrm{~A}$ & $0,960 \mathrm{~A}$ \\
\hline & C2 (Xai-32) & $1,896 \mathrm{~A}$ & $1,022 \mathrm{~A}$ & $1,010 \mathrm{~A}$ \\
\hline & C3 (5454) & $1,924 \mathrm{~A}$ & $1,021 \mathrm{~A}$ & $0,993 \mathrm{~A}$ \\
\hline & P1 $(0-20 \mathrm{~cm})$ & $3,113 \mathrm{~A}$ & $1,405 \mathrm{~A}$ & $1,601 \mathrm{~A}$ \\
\hline & P2 $(20-40 \mathrm{~cm})$ & $1,552 \mathrm{~B}$ & $0,906 \mathrm{~B}$ & $0,958 \mathrm{~B}$ \\
\hline & P3 $(40-60 \mathrm{~cm})$ & $1,586 \mathrm{~B}$ & $0,915 \mathrm{~B}$ & $0,852 \mathrm{BC}$ \\
\hline & P4 $(60-80 \mathrm{~cm})$ & $1,635 \mathrm{~B}$ & $0,931 \mathrm{~B}$ & $0,788 \mathrm{C}$ \\
\hline & P5 $(80-100 \mathrm{~cm})$ & $1,325 \mathrm{~B}$ & $0,853 \mathrm{~B}$ & $0,739 \mathrm{C}$ \\
\hline
\end{tabular}

camada de areia $(0-20 \mathrm{~cm})$ e as demais camadas. A massa seca total de raízes aos 70 DAS, também mostrou diferença significativa entre a primeira e as camadas mais profundas. Aos 124 DAS observou-se diferença significativa entre a primeira e as demais profundidades. A segunda camada (20-40 $\mathrm{cm}$ ) oscilou quanto a massa de raízes, das camadas 60-80 e 80$100 \mathrm{~cm}$. As três camadas inferiores não diferenciaram entre si.

Quando se comparam o comprimento, a densidade e a massa seca de raízes das três cultivares de alfafa, observa-se que as médias obtidas (Tabela 3) não apresentaram diferenças significativas, aos 70 nem aos 124 DAS.

Os valores de massa seca de raízes das três cultivares de alfafa, aos 124 DAS, aproximaram-se daqueles registrados por Carter et al. (1982) e foram inferiores aos constatados por Cralle \& Heichel (1981).

Os valores referentes ao teste $\mathrm{F}$ para número de nódulos, massa fresca de nódulos e massa seca de nódulos nas diferentes profundidades em duas épocas de avaliação, foram significativos $(\mathrm{P}<0,01)$ para as profundidades $(\mathrm{P})$; já para as cultivares e interação das cultivares de alfafa não houve diferença significativa. As médias para número de nódulos (Tabela 4) obtidas para cinco profundidade, apresentaram diferença significativa entre a primeira $(0-20 \mathrm{~cm})$ e as demais profundidades, verificando-se maior número de nódulos na primeira camada $(0-20 \mathrm{~cm})$, confirmando as informações de Heichel (1983). Quando foram comparados os números de nódulos das três cultivares de alfafa, constatou-se que as médias obtidas (Tabela 4) não diferiram entre si. Apesar de não terem sido analisadas estatisticamente, notou-se que entre as duas épocas de avaliação ocorreu aumento consistente e esperado no número de nódulos para as três cultivares, sendo o aumento maior para a cultivar 5454, seguida das cultivares Xai-32 e Crioula. As médias para massa fresca de nódulos obtidas para as cinco profundidades aos 70 dias (Tabela 4) indicaram diferença significativa na massa fresca de nódulos apenas entre a primeira e as demais profundidades, não se observando nodulação e, conseqüentemente, não diferiram entre si. Aos 124 DAS a primeira camada diferiu das demais, enquanto a segunda oscilou da última e as demais não apresentaram diferença estatisticamente significativa entre si.

Quando se compara a massa fresca de nódulos das três cultivares, nota-se que as médias obtidas foram semelhantes entre si, dentro de cada idade (Tabela 4). As médias para massa seca de nódulos obtidas para as cinco profundidades aos 70 DAS (Tabela 4) indicaram diferença significativa na massa seca de nódulos apenas entre a primeira e as demais profundidades,

Tabela 4. Valores médios ${ }^{\S}$ de número $(\mathrm{N})$, massa fresca (MF) e massa seca (MS) de nódulos de três cultivares de alfafa, nas diferentes profundidades, em duas épocas de avaliação

\begin{tabular}{|c|c|c|c|c|}
\hline \multirow{2}{*}{ Época } & \multirow{2}{*}{ Estatísticas } & \multicolumn{3}{|c|}{ Variáveis Estudadas (Sistema radicular) } \\
\hline & & $\mathrm{N}^{+}$ & $\mathrm{MF}^{+}$ & $\mathrm{MS}^{+}$ \\
\hline & F para cultivar $(C)$ & $1,62^{\mathrm{ns}}$ & $0,30^{\mathrm{ns}}$ & $0,01^{\mathrm{ns}}$ \\
\hline & Profundidade $(\mathrm{P})$ & $167,04^{* *}$ & $82,97^{* *}$ & $68,98^{* *}$ \\
\hline & Interação (CxP) & $1,62^{\mathrm{ns}}$ & $0,30^{\mathrm{ns}}$ & $0,01^{\mathrm{ns}}$ \\
\hline & CV (\%) parcela & 13,44 & 0,71 & 0,10 \\
\hline & CV (\%) subparcela & 36,03 & 0,71 & 0,10 \\
\hline \multirow{13}{*}{70 dias } & C1 (Crioula) & $1,399 \mathrm{~A}$ & $0,713 \mathrm{~A}$ & $0,708 \mathrm{~A}$ \\
\hline & C2 (Xai-32) & $1,678 \mathrm{~A}$ & $0,712 \mathrm{~A}$ & $0,708 \mathrm{~A}$ \\
\hline & C3 (5454) & $1,512 \mathrm{~A}$ & $0,713 \mathrm{~A}$ & $0,708 \mathrm{~A}$ \\
\hline & $\mathrm{P} 1(0-20 \mathrm{~cm})$ & $4,819 \mathrm{~A}$ & $0,734 \mathrm{~A}$ & $0,710 \mathrm{~A}$ \\
\hline & $\mathrm{P} 2(20-40 \mathrm{~cm})$ & $0,707 \mathrm{~B}$ & $0,707 \mathrm{~B}$ & $0,707 \mathrm{~B}$ \\
\hline & P3 (40-60 cm) & $0,707 \mathrm{~B}$ & $0,707 \mathrm{~B}$ & $0,707 \mathrm{~B}$ \\
\hline & P4 $(60-80 \mathrm{~cm})$ & $0,707 \mathrm{~B}$ & $0,707 \mathrm{~B}$ & $0,707 \mathrm{~B}$ \\
\hline & P5 $(80-100 \mathrm{~cm})$ & $0,707 \mathrm{~B}$ & 0,707 B & $0,707 \mathrm{~B}$ \\
\hline & F para cultivar $(C)$ & $0,13^{\mathrm{ns}}$ & $0,86^{\mathrm{ns}}$ & $0,67^{\mathrm{ns}}$ \\
\hline & Profundidade $(\mathrm{P})$ & $55,45^{* *}$ & $99,79^{* *}$ & $40,17^{* *}$ \\
\hline & Interação (CxP) & $0,48^{\mathrm{ns}}$ & $1,52^{\mathrm{ns}}$ & $1,04^{\mathrm{ns}}$ \\
\hline & CV $(\%)$ parcela & 98,94 & 8,45 & 0,72 \\
\hline & CV (\%) subparcela & 48,91 & 5,00 & 0,82 \\
\hline \multirow{8}{*}{124 dias } & C1 (Crioula) & $6,407 \mathrm{~A}$ & $0,762 \mathrm{~A}$ & $0,713 \mathrm{~A}$ \\
\hline & C2 (Xai-32) & $7,012 \mathrm{~A}$ & $0,767 \mathrm{~A}$ & $0,715 \mathrm{~A}$ \\
\hline & C3 (5454) & $7,385 \mathrm{~A}$ & $0,785 \mathrm{~A}$ & $0,714 \mathrm{~A}$ \\
\hline & P1 $(0-20 \mathrm{~cm})$ & $18,199 \mathrm{~A}$ & $0,947 \mathrm{~A}$ & $0,731 \mathrm{~A}$ \\
\hline & P2 $(20-40 \mathrm{~cm})$ & $6,035 \mathrm{~B}$ & $0,752 \mathrm{~B}$ & $0,711 \mathrm{~B}$ \\
\hline & P3 $(40-60 \mathrm{~cm})$ & $4,891 \mathrm{BC}$ & $0,725 \mathrm{BC}$ & $0,709 \mathrm{~B}$ \\
\hline & P4 $(60-80 \mathrm{~cm})$ & $4,114 \mathrm{BC}$ & $0,724 \mathrm{BC}$ & $0,709 \mathrm{~B}$ \\
\hline & P5 $(80-100 \mathrm{~cm})$ & $1,432 \mathrm{C}$ & $0,707 \mathrm{C}$ & $0,710 \mathrm{~B}$ \\
\hline
\end{tabular}

Médias seguidas de letras iguais na mesma coluna, não diferem pelo teste de Tukey, a $5 \%$ de probabilidade

Dados transformados em $\sqrt{X+0,5}$

"Significativo a $1 \%$ de probabilidade; ns Não significativo 
as quais não diferiram entre si. Aos $124 \mathrm{DAS}$, a primeira camada diferiu das demais que, no entanto, não diferiram entre si. Quando se compara a massa seca de nódulos das três cultivares, observa-se que as médias obtidas são semelhantes entre si, dentro de cada idade (Tabela 4). Os valores referentes ao teste $\mathrm{F}$ para número de nódulos total e razão parte aérea/raiz não foram significativos na avaliação feita aos 70 e 124 DAS. As médias para número de nódulos total, para as três cultivares de alfafa nas duas avaliações (Tabela 5) não apresentaram diferença significativa, embora observa aumento no número de nódulos total para as três cultivares, aos 124 dias. As médias para razão parte aérea/raiz, obtidas para as três cultivares de alfafa (Tabela 5) não apresentaram diferença significativa.

As médias para massa seca de nódulos total obtidas para as três cultivares de alfafa (Tabela 6) não indicaram diferença significativa, observando-se aumento na massa seca de nódulos total para as três cultivares, aos 124 DAS.

Tabela 5. Valores médios ${ }^{\S}$ de número de nódulos total (NT) e razão parte aérea/raiz (PA/R) para três cultivares de alfafa, em duas épocas de avaliação

\begin{tabular}{|c|c|c|c|}
\hline \multirow{2}{*}{ Época } & \multirow{2}{*}{ Estatística } & \multicolumn{2}{|c|}{ Variáveis Estudadas } \\
\hline & & $\mathrm{NT}^{+}$ & Razão PA/R $\left(\mathrm{g} \mathrm{g}^{-1}\right)^{++}$ \\
\hline \multirow{5}{*}{70 dias } & Crioula & $4,10 \mathrm{~A}$ & $1,394 \mathrm{~A}$ \\
\hline & Xai-32 & $5,51 \mathrm{~A}$ & $1,574 \mathrm{~A}$ \\
\hline & 5454 & $4,67 \mathrm{~A}$ & $1,715 \mathrm{~A}$ \\
\hline & F (tratamento) & $1,61^{\mathrm{ns}}$ & $2,51^{\mathrm{ns}}$ \\
\hline & CV $(\%)$ & 26,25 & 14,51 \\
\hline \multirow{5}{*}{124 dias } & Crioula & $21,10 \mathrm{~A}$ & $1,483 \mathrm{~A}$ \\
\hline & Xai-32 & $20,86 \mathrm{~A}$ & $1,433 \mathrm{~A}$ \\
\hline & 5454 & $22,03 \mathrm{~A}$ & $1,523 \mathrm{~A}$ \\
\hline & F (tratamento) & $0,01^{\mathrm{ns}}$ & $0,07^{\mathrm{ns}}$ \\
\hline & CV $(\%)$ & 32,43 & 26,33 \\
\hline
\end{tabular}

Tabela 6. Valores médios ${ }^{\S}$ de massa seca de nódulos, massa seca de raiz e massa seca total da planta de três cultivares de alfafa, em duas épocas de avaliação

\begin{tabular}{|c|c|c|c|c|}
\hline \multirow{2}{*}{ Época } & \multirow{2}{*}{ Estatística } & \multicolumn{3}{|c|}{$\begin{array}{l}\text { Variáveis Estudadas/Massa seca } \\
\text { (g/planta) }\end{array}$} \\
\hline & & $\begin{array}{l}\text { Nódulos } \\
\text { total }^{+}\end{array}$ & $\begin{array}{l}\text { Raiz } \\
\text { total }^{++}\end{array}$ & $\begin{array}{c}\text { Total } \\
\text { da planta }\end{array}$ \\
\hline \multirow{5}{*}{70 dias } & Crioula & $0,0044 \mathrm{~A}$ & $0,835 \mathrm{~A}$ & $0,4971 \mathrm{~A}$ \\
\hline & Xai-32 & $0,0048 \mathrm{~A}$ & $0,867 \mathrm{~A}$ & $0,7226 \mathrm{~A}$ \\
\hline & 5454 & $0,0045 \mathrm{~A}$ & $0,807 \mathrm{~A}$ & $0,5043 \mathrm{~A}$ \\
\hline & F (tratamento) & $0,04^{\mathrm{ns}}$ & $2,12^{\mathrm{ns}}$ & $4,19^{*}$ \\
\hline & $\mathrm{CV}(\%)$ & 47,26 & 5,47 & 24,38 \\
\hline \multirow{5}{*}{124} & Crioula & $0,0440 \mathrm{~A}$ & $1,965 \mathrm{~A}$ & $9,404 \mathrm{~A}$ \\
\hline & Xai-32 & $0,0455 \mathrm{~A}$ & $1,919 \mathrm{~A}$ & $12,464 \mathrm{~A}$ \\
\hline & 5454 & $0,0639 \mathrm{~A}$ & $1,848 \mathrm{~A}$ & $11,848 \mathrm{~A}$ \\
\hline & F (tratamento) & $1,46^{\mathrm{ns}}$ & $0,06^{\mathrm{ns}}$ & $0,31^{\mathrm{ns}}$ \\
\hline & $\mathrm{CV}(\%)$ & 40,29 & 28,72 & 58,22 \\
\hline
\end{tabular}

As médias para massa seca de raiz total obtidas para as três cultivares de alfafa (Tabela 6) foram semelhantes entre si, seja aos 70 ou aos 124 DAS. Os valores referentes ao teste $F$ para massa seca total de plantas foram significativos $(\mathrm{P}<0,05)$ somente na avaliação realizada aos 70 dias após a semeadura. As médias para massa seca total da planta obtidas para três cultivares de alfafa (Tabela 6) não indicaram diferença significativa, observando-se aumento da massa seca total da planta para as três cultivares, aos 124 DAS.

\section{CONCLUSÕES}

1. Para algumas características analisadas, encontrou-se variabilidade genética entre as três cultivares estudadas, principalmente aos 70 dias após a semeadura.

2. Os maiores valores de densidade de comprimento e de massa seca radicular foram encontrados na camada superior do solo.

3. As três cultivares de alfafa não diferiram entre si quanto ao número total de nódulos e à razão parte aérea/raiz.

\section{LITERATURA CITADA}

Bordeleau, L.M.; Prévost, D. Nodulation and nitrogen fixation in extreme environments. Plant and Soil, Dordrecht, v.161, p.115-125, 1994.

Carter, P.R.; Sheaffer, C.C.; Voorhees, W.B. Root growth, herbage yield, and plant water status of alfalfa cultivars. Crop Science, Madison, v.22, p.425-7, 1982.

Cralle, H.T.; Heichel, G.H. Nitrogen fixation and vegetative regrowth of alfalfa and birdsfoot trefoil after successive harvests or floral debudding. Plant Physiology, Walthan, v.67, p.898-905, 1981.

Edmisten, K.L.; Wolf, D.D. Fall harvest management of alfalfa. II. The implications of photosynthesis, respiration, and taproot nonstructural carbohydrate accumulation on fall harvest management. Agronony Journal, Madson, v.80, p.693-698, 1988 .

Fick, G.W.; Holt, D.A.; Lugg, D.G. Environmental physiology and crop growth. In: Hanson, A.A. (ed.) Alfalfa and alfalfa improvement. Madison: American Society of Agronomy, 1988.p.163-193. Agronomy Monograph, 29.

Goins, G.D.; Russele, M.P. Fine root demography in alfalfa (Medicago sativa L.). Plant and Soil, Dordrecht, v.185, p.281291, 1996.

Heichel, G.H. Alfalfa. In: Teare, I.D.; Peet, M.M. Crop-water relations. New York : John Wiley, 1983. cap.4, p.128-155.

McLaughlin, R.J.; Christie, B.R. Genetic variation for temperature response in alfalfa (Medicago sativa L.). Canadian Journal of Plant Science, Ottawa, v.60, p.547-54, 1980.

Mitidieri, J. Manual de gramíneas e leguminosas para pastos tropicais. São Paulo: Nobel, 1983. p.198.

Monteiro, A.L.G. Fisiologia do crescimento. In: Simpósio sobre Manjo da Pastagem: Alfafa, 16, 1999, Piracicaba. Anais... p. $23-45$. 
Monteiro, A.L.G.; Costa, C.; Silveira, A.C. Produção e distribuição de matéria seca e composição bromatológica de cultivares de alfafa (Medicago sativa L.). Revista Brasileira de Zootecnia, Viçosa, v. 27, n.5, p.868-874, 1998.

Nabinger, C.; Maraschin, G.E.; Moraes, A. Pasture related problems in beef cattle production in southern Brazil. In: Symposium International Grassland and Ecophysiology and Granzing Ecology, 1999, Curitiba. Anais... p.23-48.

Nelson, C.J.; Smith, D. Growth of birdsfoot trefoil and alfalfa. II. Morphological development and dry matter distribution. Crop Science, Madison, v.8, p.21-5, 1968.

Nuernberg, N.J.; Milan, P.A.; Silveira, C.A.M. Manual de produção de alfafa. Florianópolis: EMPASC, 1990. p.102.

Passos, L.P. Indicadores fisiológicos para a cultura da alfafa nos trópicos. In: Botrel, M.A. (ed.) Workshop sobre potencial forrageiro da alfafa (Medicago sativa L.) nos trópicos. Juiz de Fora: Embrapa-CNPGL, 1994, p. 149-158.
Rodrigues, T.J.D. Drought resistance mechanisms among peanut genotypes. Gainesville: University of Florida. 1984, 117p. Ph D Thesis

Silva, G.;M.; Chahin, A.;G.; Soto, S.;M. Desarrolo y valor nutritivo de la alfalfa (Medicago sativa L.). Avances en Producción Animal, Santiago, v. 21, n.1-2, p.13-22, 1996.

Singh, Y.; Winch, J.E. Morphological development of two alfalfa cultivars under various harvesting schedules. Canadian Journal Plant Science, Ottawa, v.54, p.79-87, 1974.

Tennant, D. A test of a modified line intersect method of estimating root length. Journal of Ecology, Oxford, v.63, p.9951001, 1975.

Youngner, V.B. Physiology of defoliation and regrowth. In: Youngner, V. B.; McKell, C.M. (ed.) The biology and utilization of grasses. New York: Academic Press, 1972. p.292303. 